\title{
EXPERIMENTAL ACTIVE CONTROL OF A TYPICAL SECTION AIRFOIL USING A TRAILING EDGE FLAP
}

\author{
J e®rey S. Vipperman ${ }^{\ltimes} \quad$ Robert L. Clark y $\quad$ Mark Conner ${ }^{z}$ \\ Earl H. Dowell $x$ \\ Department of Mechanical Engineering and Materials Science \\ B ox 90300 \\ Duke University, Durham, NC 27708-0300
}

J une 26, 1997

\begin{abstract}
A bstract
This paper presents an experimental implementation of an active control system used to suppress ${ }^{\circ}$ utter in a typical section airfoil. The $\mathrm{H}_{2}$ optimal control system design is based upon experimental system identi ${ }^{-}$cations of the transfer functions between three measured system variables: pitch, plunge, and ${ }^{\circ}$ ap position and a single control signal which commands the ${ }^{\circ}$ ap of the airfoil. Closed-loop response of the airfoil demonstrated gust-alleviation below the openloop ${ }^{\circ}$ utter-boundary. In addition, the ${ }^{\circ}$ utter boundary was extended by $12.4 \%$ through the application of active control. Cursory robustness tests demonstrate stable control for variations in ${ }^{\circ}$ ow-speed of $\S 10 \%$.

\footnotetext{
${ }^{x}$ Graduate Research A ssistant, Student M ember AIA A

${ }^{y}$ A ssistant Professor, Member AIAA

${ }^{\mathrm{Z}} \mathrm{G}$ raduate Research A ssistant

${ }^{\times}$Dean of Engineering, J . B. J ones Professor of M echanical Engineering and Materials Science, Fellow AIAA
} 


\section{Introduction}

Active control of articulated aerodynamic control surfaces has been a topic of interest for many years. Various control strategies including classical, modern (LQR/LQG) and robust $\left(\mathrm{H}_{1}\right)$ have been applied to structures ranging in complexity from typical sections, ${ }^{1}$ to cantilevered wings. ${ }^{2 \nmid 4}$ The objective has typically been two-fold: provide gust alleviation for ride quality and extend the ${ }^{\circ}$ utter boundary for performance. While a signi ${ }^{-}$cant eßort has been devoted to analytical studies, ${ }^{5\{10}$ there are fewer experimental implementations of closed-loop controllers. ${ }^{1\{4,11}$ At NASA Langley Research Center, the Benchmark Active Controls Testbed $(B A C T)^{12}$ has been used to generate extensive test data and dynamic model $s^{13}$ dedicated to the study of ${ }^{\circ}$ utter suppression controllers. The physics associated with the control problem are well described by Edwards et al., ${ }^{6} \mathrm{~K}$ arpel, ${ }^{14}$ and Lazarus et al. ${ }^{15}$

T he objective of the proposed eßort was to investigate experimentally, the closed-loop performance of a three degree-of-freedom (dof) typical section using a trailing edge ${ }^{\circ}$ ap as the control input and measures of pitch, plunge and ${ }^{\circ}$ ap actuator position as sensor variables. While analytical models of the system have been developed, 8,16,17 an experimental system identi ${ }^{-}$cation was performed at each dynamic pressure ( ${ }^{\circ}$ ow speed) for which the controller was designed. A $n$ $\mathrm{H}_{2}$ controller was designed which minimized the power associated with pitch, plunge, and ${ }^{\circ}$ ap position upon exciting each state of the measured system with stochastic noise sources. The objective was to create a compensator which would provide gust alleviation at ${ }^{\circ}$ ow speeds well below the ${ }^{\circ}$ utter boundary and extend the ${ }^{\circ}$ utter boundary at the upper limit. Based upon the experimental system identi ${ }^{-}$cation, both predicted and measured performance are compared.

Since the poles and zeros of the dynamic system vary as a function of dynamic pressure ( ${ }^{\circ}$ ow speed for wind-tunnel experiments), the compensators demonstrated limited robustness to variation in ${ }^{\circ}$ ow speed. In general, the controllers provided stability at ${ }^{\circ}$ ow speeds $\S 10 \%$ of that for which they were designed. Thus, it is not unreasonable to expect a limitation in the extension of the ${ }^{\circ}$ utter boundary beyond $10 \%$. However, once the ${ }^{\circ}$ utter boundary is extended, one can identify the system response at the higher ${ }^{\circ}$ ow speed and use this data to design a 
controller which will stabilize the system at yet higher ${ }^{\circ}$ ow speeds. Since gain scheduling is required, one could identify the closed-loop system on-line and use this data to determine the compensator necessary for operation at higher dynamic pressures.

\section{Control Strategy}

The control system was synthesized by casting the aeroelastic control problem into a twoport con ${ }^{-}$guration using linear quadratic Gaussian (LQG)-style weighting parameters as shown in Figure 1. From Figure 1, the generalized plant, $\mathrm{G}(\mathrm{s})$ consists of the Aeroelastic model, $\mathrm{fA} ; \mathrm{B} ; \mathrm{C} ; \mathrm{Dg}$ as well as subsystems which determine the frequency-domain shape of the process noise, sensor noise, control penalty and performance penalty, which were chosen to be $1^{\circ}$ at" or all-pass. Also from Figure $1, w(t)$ is a vector of disturbance inputs composed of process noise, $\gg(t)$, and sensor noise, $\mu(t)$, which were assumed to be uniform random processes. For simplicity, each state of the aeroelastic model was excited uniformly by the process noise, $\gg(t)$ : The output, $z(t)$, is an error or performance vector which allows the performance objective (minimize pitch, plunge and ${ }^{\circ} a p$ ) to be traded $0{ }^{\circledR}$ with control eßort. Finally, the vector $y(t)$ is the set of measured variables (pitch, plunge and actuator position) which are fed back to form the scalar control signal, $u(t)$ that commands the ${ }^{\circ} a p$.

Note that the variables measured in vector $\mathrm{y}(\mathrm{t})$ that are fed back to form the control signal are also the plant variables that partially comprise the performance penalty, $z(t)$; and are thus minimized by the controller. An experimental system identi ${ }^{-}$cation is performed to determine the A eroelastic model, f A ; B ; C ; D g: A total of 27 states were used in the curve ${ }^{-}{ }^{-}$which allowed the less-signi ${ }^{-}$cant dynamics to be modelled as well.

The objective is to ${ }^{-}$nd the controller which minimizes the $\mathrm{k}_{\mathbf{w z}} \mathrm{k}_{2}$ of the closed-loop transfer function from $w$ to $z$ : $T_{\mathbf{w z}}$, (Doyle, et al., 1989), where

$$
k T_{\mathbf{w z}} k_{2}:={\frac{1}{2^{1} / 4}{ }_{i 1}}^{Z_{1}} \operatorname{trace}\left[T_{\mathbf{w z}}(j !)^{\mathbb{x}} T_{\mathbf{w z}}(j !)\right] d !^{\mathfrak{q}_{1=2}}
$$

where $k \phi k_{2}$ is the 2-norm, $T_{w z}$ is the transfer function from $w$ to $z$ (disturbance input to

performance output), ${ }^{x}$ denotes the complex conjugate operator, $j={ }^{p} \overline{i 1}$, and ! is the natural 
circular frequency. A block diagram of the quadruple describing the system is illustrated in Figure 2. The input signals represented by the vector, w, contain both sensor noise and the disturbance, while $z$ is vector of performance output signals which for the given system includes both the error signals and the control eßort signal. The control input to the moving coil transducer is represented by $u$, and the measured signals are represented by $y$. If a frequency weighted cost functional is desired, one can readily replace the static or all-pass ${ }^{-}$Iters included within this model with dynamic "Iters in formulating the augmented system. Thus, for the chosen formulation, the LQG problem is embedded within the augmented system. The formal solution for the unique optimal controller can be found in the reference by Doyle et al. ${ }^{18}$

\section{System Description}

Wing M odel

The experimental model is shown in Figure 3. The NACA 0012 rectangular wing model includes two parts, a main wing with a $19 \mathrm{~cm}$ chord and $52 \mathrm{~cm}$ span and a ${ }^{\circ}$ ap with a $6.35 \mathrm{~cm}$ chord and $52 \mathrm{~cm}$ span, which is mounted at the trailing edge of the main wing using two pairs of micro-bearings with pins allowing the ${ }^{\circ}$ ap to have a rotational degree-of-freedom relative to the main wing. The main wing is constructed from an aluminum alloy circular spar beam with a diameter of $2.54 \mathrm{~cm}$ and a wall thickness of $0.32 \mathrm{~cm}$. The beam runs through 14 pieces of NACA 0012 aluminum airfoil plate and serves as the pitch axis, located at the quarter-chord location from the leading edge. A $0.254 \mathrm{~mm}$ thick aluminum sheet covers the entire chord and span, providing the aerodynamic contour of the wing. The ${ }^{\circ}$ ap is constructed in a similar manner with an aluminum alloy tube spar beam $(1.27 \mathrm{~cm}$ diameter and $0.16 \mathrm{~cm}$ wall thickness) passed through the leading edge of 14 pieces of NACA 0012 wood airfoil plate. The ${ }^{\circ}$ ap is also covered with the same type of aluminum sheet.

The model dimensions were chosen to try to maintain a two-dimensional ${ }^{\circ}$ ow ${ }^{-}$eld by minimizing the end eßects and (thickness to wall-separation). Inertial and sti §ness parameters were chosen to yield $a^{\circ}$ utter speed that was well below the maximum attainable speed for the wind 
tunnel.

\section{Support Structure}

As seen in Figure 3, the model is mounted vertically in the wind tunnel. The support mechanisms for the model are mounted outside of the wind tunnel, at the top and bottom. Each support mechanism consists of a guided cantilever beam ${ }^{19}$ made of two steel leaf springs which are $20.32 \mathrm{~cm}$ long, $2.86 \mathrm{~cm}$ wide and $0.102 \mathrm{~cm}$ thick. Figure 4 shows the upper support mechanism which is identical to its lower counterpart. The distance between the two leaf springs which make up each guided cantilever beam is $15.24 \mathrm{~cm}$. A support block joins the free ends of the two leaf springs and these upper and lower support blocks move with the model along the plunge degree-of-freedom. The pitch axis of the main wing is mounted to the upper and lower support blocks through a pair of precision bearings which have a small amount of dry

friction in the ball. At the upper bracket, there is a spring wire which is press- ${ }^{-} t$ through the center of the shaft that forms the pitch axis and simply-supported at each end to form the pitch sti ßness. Supports at each end of the spring wire can be moved in or out to increase or decrease, respectively, the sti ®ness of the pitch axis. The sti ®ness and inertial properties of the airfoil before the addition of the control actuator assembly can be found in the literature. ${ }^{16}$

\section{Control Actuator Assembly}

A schematic of the experimental control assembly is shown in Figure 5. A BEI linear actuator, LA 13-12-000A, serves as the means of applying the required control force to the experimental model. The "eld assembly has a diameter of $3.16 \mathrm{~cm}$, and the coil assembly has a diameter of $2.6 \mathrm{~cm}$. The actuator has a free stroke of $\S 0: 3175 \mathrm{~cm}$, with a total length ( ${ }^{-}$eld and coil assemblies) of $2.86 \mathrm{~cm}$ at mid-stroke. The system can apply a peak force of $15.57 \mathrm{~N}$ and a blocked force of $7.12 \mathrm{~N}$. The ${ }^{-}$eld assembly is held stationary in a support block that is mounted to a base plate used to support all of the control system hardware. T wo precision linear bearings

are mounted on the base plate and support a mating precision shaft that is threaded into the center of the coil assembly. The bearings allow the coil assembly to move in and out of the ${ }^{-}$eld 
assembly while maintaining the speci ${ }^{-}$ed clearance between the two. The base plate containing all of the control system hardware is mounted at one end of the wing model, as shown in Figure 6. The total mass of the actuator assembly is $0.419 \mathrm{~kg}$.

The position of the coil assembly is measured using a Lucas Schaevitz 250 MHR linear variable displacement transducer (LVDT), shown in Figure 5. The core of the LVDT is attached to the shaft, and the body of the LVDT is mounted in a support block. In addition to the actuator position, two other displacement measurements are also fed back for the system control. The pitch angle of the main wing is measured by a rotational variable displacement transducer (RVDT) which is ${ }^{-}$xed at the upper end of the pitch axis. The plunge displacement is measured using another RVDT which remains stationary relative to the motion of the upper support block. Figure 4 denotes the two RVDT s used to measure pitch and plunge. The three measurement signals are independent of each other.

Since the linear motion of the actuator is being converted into the rotational motion of the ${ }^{\circ}$ ap, a small amount of ${ }^{\circ}$ exibility in the connection is required. The actuator shaft and the shaft extending from the control surface are perpendicular to each other and are joined by a thin, rectangular piece of fairly sti ${ }^{\circledR}$ spring steel, which keeps the actuator shaft from binding as it moves through its entire range of travel. A moment arm that is $2.0 \mathrm{~cm}$ long is achieved by the - exible linkage. The entire control assembly is mounted to the lower end of the wing-aileron. A cutout must be made in the ${ }^{\circ}$ oor of the tunnel to allow the actuator assembly to extend beyond the main wind tunnel test section. The cutout is large enough for the control assembly and allows for a reasonable range of motion. Since the control system is mounted to the main wing, the entire assembly will pitch and plunge with the airfoil. Flap actuator position was fed back to the control system in lieu of ${ }^{\circ}$ ap angle since slightly better coherence with the command signal was measured. The actuator/aileron connector shim added a damped resonance at 125 $\mathrm{Hz}$, which is much higher than the dynamics of the typical section. Measured frequency response functions (FRFs) between ${ }^{\circ}$ ap angle and control input and ${ }^{\circ}$ ap actuator position and control input are identical between $0-20 \mathrm{~Hz}$, which encompasses the dynamics of the typical section. 
Measured airfoil resonances at $6.34,11.0$, and $12.4 \mathrm{~Hz}$ (in the absence of ${ }^{\circ}$ ow) are associated with plunge, pitch, and ${ }^{\circ} \mathrm{ap}$, degrees-of-freedom respectively.

W ind Tunnel

All tests of the two-dimensional wing model were performed in the Duke University low speed wind tunnel. The wind tunnel is a closed circuit tunnel with a test section of $0.70 \mathrm{mx}$ $0.51 \mathrm{~m}$ and a length of $1.22 \mathrm{~m}$. The maximum attainable air speed is $89 \mathrm{~m} / \mathrm{s}$. The stagnation temperature of the airstream is held constant over the range $15^{\circ} \mathrm{C}$ to $38^{\circ} \mathrm{C}$ by means of an external air exchange system and tunnel stagnation pressure equals atmospheric pressure at the low Reynolds number operating conditions. For the present test, the Reynolds number based upon model chord is $0: 52 \times 10^{6}$.

\section{Controller Implementation}

The control designs were implemented in discrete time on a T M S320C 31-based digital signal processor (DSP) board manufactured by Spectrum Signal Processing, Inc. A Spectrum Signal Processing 16-input, 8-output Multi-l/ O board was used to sample the continuous time signals as well as reconstruct digital signals back into analog. Each control design was discretized using a Tustin transform. ${ }^{20}$ The controller parameters were downloaded to the DSP using a Pentium ${ }^{T M}$-based computer, which hosted the DSP board.

The sampling rate was set to $2 \mathrm{kHz}$ for all experiments, which provided ample bandwidth for the control problem, which mainly focused on dynamics in a $0-20 \mathrm{~Hz}$ frequency band. Most control systems had 25 states after a very modest model reduction, but the ${ }^{-}$nal control system which was based on a system identi ${ }^{-}$cation performed on a closed-loop system above the original ${ }^{\circ}$ utter boundary contained 61 states.

\section{System Identi ${ }^{-}$cation}

In order to design a controller for experimental implementation, a system identi ${ }^{-}$cation of the wind tunnel model has been performed. A Tektronix 2630 Spectrum Analyzer was used 
to calculate the frequency response functions ( $F R F s$ ) and coherences between a random input to the actuator and the resulting responses from each of the three outputs: pitch, plunge and actuator displacements. The random input signal generated by the Tektronix analyzer was ampli' ed by a Hewlett-Packard 6825A Bipolar Power Supply/A mpli ${ }^{-}$er and then sent to the terminals of the linear actuator.

Frequency response function (FRF) data were recorded for the linear system for freestream conditions ranging from no freestream velocity to speeds near the ${ }^{\circ}$ utter boundary. SmartID ${ }^{21}$ software was then used to do a multi-variable system identi ${ }^{-}$cation and provide a state-space model of the aeroelastic system. U sing twenty-seven states to model the dynamics of the system provided adequate ${ }^{-}$ts for the magnitude and phase for all three transfer functions at each of the ${ }^{\circ}$ ow conditions. The measured magnitude and phase along with the approximation from the system identi ${ }^{-}$cation is shown in Figure 7 for a representative ${ }^{\circ}$ ow condition, $18.1 \mathrm{~m} / \mathrm{s}$. The approximations, which are shown by the dotted lines, match well with both the magnitude and phase of the experimentally measured F R Fs which are shown by the solid lines. Each frequencydomain experimental FRF has the $95 \%$ con $^{-}$dence bounds plotted in very thin lines. It is di \pm cult to see the narrow lines that mark the con $^{-}$dence bounds in Figure 7 since they are nearly coincident with the bold lines that represent the data. The con ${ }^{-}$dence bounds are computed using the estimate of the coherence function between the input and output signals for the FRF, which takes into account many bias errors including input noise, estimation biases, nonlinearities and time-varying properties. The ${ }^{\circ}$ utter speed for the experimental system without control is approximately $18.6 \mathrm{~m} / \mathrm{s}$.

It should be noted that the coherence between the random input to the actuator and the pitch and plunge motion of the typical section model increases as the freestream velocity increases. W ith the increase in airspeed comes an increase in the ${ }^{\circ}$ uid-structure coupling that characterizes aeroelastic systems. The increased coupling allows for a more accurate system identi ${ }^{-}$cation and more controllability, which ameliorates control system design. 


\section{R esults}

Controllers were designed based upon each of the system identi- cations discussed previously. For the sake of brevity, only two of the pre- ${ }^{\circ}$ utter cases will be discussed here. Also, only the magnitude portion of the frequency responses is shown, although the phase data also showed very good correlation.

\section{\Low" Freestream Velocity}

Figure 8 (a) - (c) shows the predicted open and closed loop frequency responses for pitch, plunge and actuator displacements, respectively, for a controller designed for an operating ${ }^{\circ}$ ow speed of $12.5 \mathrm{~m} / \mathrm{s}$. The Ipredicted" responses are obtained by coupling the control designs with the state-space aeroelastic models obtained from the system identi ${ }^{-}$cation process. The experimental frequency responses are shown in parts (d) - (f), including the $95 \%$ con $^{-}$dence bounds in very thin lines, which again are nearly coincident with the data. The predicted frequencies for the primary and secondary peaks are slightly higher than those of the actual system, though they match well in magnitude. The closed loop responses are very similar in nature, showing a signi ${ }^{-}$cant decrease in the magnitude of the primary peak along with an increase in magnitude at the secondary peak. The numerical model did predict a reduction of approximately $20 \mathrm{~dB}$ at the primary peak, while the actual decrease was closer to $15 \mathrm{~dB}$.

The experimental time domain responses for the pitch and plunge degrees-of-freedom at $12.5 \mathrm{~m} / \mathrm{s}$ are shown in Figure 9. The model was given an initial displacement in the plunge degree-of-freedom of $3.5 \mathrm{~mm}$ and was then released. A signi ${ }^{-}$cant increase between the overall damping of the open and closed loop systems is seen in both of the time series. The controlled system response decays in about one-fourth the time of the uncontrolled system. Con ${ }^{-}$dence bounds for the time-domain plot are not included since they were characterized in the frequency domain. 


\section{$\backslash$ High" Freestream Velocity}

The increased accuracy of the system identi ${ }^{-}$cation at higher ${ }^{\circ}$ ow conditions can be seen in F igure 10, showing the frequency response using a controller designed for an operating freestream velocity of $18.1 \mathrm{~m} / \mathrm{s}$. While the correlation between the predicted and experimental frequency responses were very good at the lower ${ }^{\circ}$ ow speed, the predicted and measured open and closed loop curves now lie almost on top of each other. The largest di ßerence occurs around $10 \mathrm{~Hz}$, where the numerical model again predicts worse behavior than is seen experimentally. The predicted $20 \mathrm{~dB}$ reduction at $4.5 \mathrm{~Hz}$ was achieved in the wind tunnel experiment.

The open-loop or uncontrolled time responses seen in Figure 11 show that the overall system damping is very low and the ${ }^{\circ}$ ow conditions are very near the ${ }^{\circ}$ utter boundary. The open-loop response continues longer than seven seconds while the closed-loop response decays in less than 1.5 seconds. These results do show great potential for increasing the ${ }^{\circ}$ utter speed.

\section{Flutter Boundary}

The ${ }^{\circ}$ utter speed for the uncontrolled system is approximately $18.6 \mathrm{~m} / \mathrm{s}$. Time series for pitch and plunge just past the uncontrolled ${ }^{\circ}$ utter boundary are shown in Figure 12. A $n$ experimental frequency response was obtained for a freestream velocity of $18.5 \mathrm{~m} / \mathrm{s}$, and the controller designed for this ${ }^{\circ}$ ow condition was used to to successfully increase the ${ }^{\circ}$ utter boundary by approximately $8 \%$. Figure 13 shows the controlled time response at $20.0 \mathrm{~m} / \mathrm{s}(8.1 \%$ above the uncontrolled ${ }^{\circ}$ utter speed). A closed loop frequency response was obtained at $20.1 \mathrm{~m} / \mathrm{s}$ and is shown in Figure 14a, with the $95 \%$ con $^{-}$dence bounds plotted in very thin lines again.

Using the post- ${ }^{\circ}$ utter closed loop frequency response, a new system identi ${ }^{-}$cation was performed to obtain a numerical model of the system operating above the uncontrolled ${ }^{\circ}$ utter boundary. The size of the numerical model increased from twenty-seven states for the pre${ }^{\circ}$ utter conditions to ${ }^{-}$fty states at $20.1 \mathrm{~m} / \mathrm{s}$. A new controller was then designed using the new numerical model in order to try to further increase the ${ }^{\circ}$ utter boundary. Figure $14 b$ shows the closed loop frequency response for the experimental system at $20.9 \mathrm{~m} / \mathrm{s}$, which represents an 
overall increase in the original ${ }^{\circ}$ utter boundary of over $12 \%$. The $95 \%$ con $^{-}$dence bounds plotted in thin lines in Figure 14b are much larger than those plotted in Figure 14a due to a decrease in the coherence estimates, presumably due to the controller interaction and larger aerodynamic excitation at the higher ${ }^{\circ}$ ow rate.

$\mathrm{O}{ }^{\wedge} \mathrm{N}$ ominal Design Performance

The erectiveness of each of the controllers away from their nominal design speed was examined numerically and experimentally. Figure 15 shows the open and closed loop pitch responses for ${ }^{\circ}$ ow conditions at, above, and below the design speed of $16.7 \mathrm{~m} / \mathrm{s}$. The predictions at the lower ${ }^{\circ}$ ow speed of $14.8 \mathrm{~m} / \mathrm{s}$ show a better correlation with the measured data, as seen in parts (a) and (c). There is a di ßerence in magnitudes at very low frequencies. The same trends are seen between the numerical and experimental data for the higher ${ }^{\circ}$ ow speed of $18.1 \mathrm{~m} / \mathrm{s}$, however, there is a noticeable di ßerence in the secondary peak. In this case, the actual response is more favorable than that predicted.

\section{Conclusions}

Active control of a typical section airfoil using a trailing edge ${ }^{\circ}$ ap as the control input and measures of pitch, plunge and ${ }^{\circ}$ ap actuator position as sensor variables was investigated. An experimental system identi ${ }^{-}$cation was performed at each dynamic pressure $\left({ }^{\circ}\right.$ ow speed for windtunnel experiments), and an $\mathrm{H}_{2}$ controller was designed for each ${ }^{\circ}$ ow condition to minimize the R M S power associated with pitch, plunge, and ${ }^{\circ}$ ap position due to stochastic disturbance sources applied across each aeroelastic state of the system. The resulting compensator provided gust alleviation at ${ }^{\circ}$ ow speeds well below the ${ }^{\circ}$ utter boundary and extended the ${ }^{\circ}$ utter boundary at the upper limit by $12.4 \%$. The predicted and measured closed-loop performance compared well over all ${ }^{\circ}$ ow conditions, and the resulting compensators designed for a $\mathrm{speci}^{-} \mathrm{C}{ }^{\circ}$ ow condition were observed to provide stable closed-loop performance at ${ }^{\circ}$ ow speeds varying between $\S 10 \%$ of the nominal.

R esults from this work also demonstrate that once the ${ }^{\circ}$ utter boundary is extended through 
the implementation of an active control system, a system identi ${ }^{-}$cation of the closed-loop system can be obtained to design a controller which further extends the ${ }^{\circ}$ utter boundary for higher ${ }^{\circ}$ ow speeds. If the controller were designed on-line, then one could identify the plant concurrently while implementing control to meet the demands of variation in dynamic pressure.

Future work will address the eßects of free-play nonlinearities between the ${ }^{\circ}$ ap actuator and the ${ }^{\circ}$ ap. In addition, methods of producing a robust control system for all operating conditions (dynamic pressures) using gain-scheduling or structured uncertainty methods will be investigated.

\section{A cknowledgements}

The authors gratefully acknowledge the A ir Force $\mathrm{O} \pm \mathrm{ce}$ of Scienti ${ }^{-} \mathrm{c}$ Research for funding this research under grant number F 49620-92-J -0491, which is monitored by M ajor B rian Sanders. In addition, the authors gratefully acknowledge David Cox of the Guidance Controls B ranch at NASA Langley Research Center for his helpful insight into the control system design. Finally, a special thanks is extended to the anonymous reviewer whose thorough review and comments helped to improve the quality of this manuscript.

\section{R eferences}

${ }^{1}$ Mukhopadhyay, V., IFlutter Suppression Control Law Design and Testing for the Active Flexible W ing," J ournal of Aircraft, Vol. 32, No. 1, 1995, pp. $45\{51$.

2 Lin, C. Y ., Crawley, E. F., and Heeg, J., IOpen Loop and Preliminary Closed Loop Results of a Strain Actuated Active A eroelastic W ing," 36th AIA A / A SME / ASCE/A HS/ ASC Structures, Structural Dynamics, and Materials Conference, New Orleans, LA, A pr. 10-13 1995, pp. $1904\{1914$.

${ }^{3}$ Ghiringhelli, G. L., Lanz, M., and Mantegazza, P., \Active Flutter Suppression for a Wing Model," J ournal of Aircraft, Vol. 27, No. 4, 1990, pp. 334\{341. 
${ }^{4}$ Pak, C., Friedmann, P. P., and Livne, E., ITransonic A daptive F lutter Suppression Using A pproximate Unsteady Time Domain Aerodynamics," 32nd AIAA/ASME/ASCE/AHS/ASC Structures, Structural Dynamics, and Materials Conference, 1991, pp. 1832\{1854.

5 Ozbay, H. and Bachmann, G. R., $\backslash \mathrm{H}_{2} / \mathrm{H}_{1}$ Controller Design for a Two-Dimensional Thin Airfoil Flutter Suppression," J ournal of Guidance, Control, and Dynamics, Vol. 17, No. 4, 1994, pp. $722\{728$.

${ }^{6}$ Edwards, J. W ., Breakwell, J . V., and B ryson, A. E ., \A ctive Flutter Control U sing Generalized Unsteady A erodynamic Theory," J ournal of Guidance and Control, Vol. 1, No. 1, 1978, pp. $32\{40$.

7 Lazarus, K. B., Crawley, E. F., and Lin, C. H., \Fundamental Mechanisms of A eroelastic Control W ith Control Surface and Strain Actuation," 32nd AIAA/ASME/A SCE/AHS/ASC Structures, Structural Dynamics, and Materials Conference, 1991, pp. 1817\{1831.

${ }^{8}$ Conner, M. D., Tang, D., Dowell, E. H., and Virgin, L. N., \A ccurate Numerical Integration of State Space Models for A eroelastic Systems W ith Freeplay," AIAA J ournal, A ccepted for Publication.

9 Newsom, J . R., I Control L aw Synthesis for A ctive F lutter Suppression U sing O ptimal Control Theory," J ournal of Guidance and Control, Vol. 2, No. 5, 1979, pp. $388\{394$.

10 Lin, C. Y. and Crawley, E. F., I Design Considerations for a Strain A ctuated A daptive Wing for A eroelastic Control," Proceedings, Fourth International Conference on Adaptive Structures, Cologne, Germany, 1993.

${ }^{11}$ Lazarus, K. B. and Crawley, E. F., \Multivariable Active Lifting Surface Control Using Strain Actuation: A nalytical and Experimental Results," Third International Conference on Adaptive Structures, 1992, pp. 87\{101. 
12 Durham, M. H., Keller, D. F., B ennett, R. M., and W ieseman, C. D., \A Status Report on a M odel for Benchmark Active Controls Testing," AIAA-91-1011, 1991.

${ }^{13}$ Waszak, M. R., \M odeling the B enchmark A ctive Control Technology W ind-T unnel M odel for A pplication to Flutter Suppression," Proceedings of the AIA A Atmospheric Flight Mechanics Conference, San Diego, CA, J uly 29-31 1996.

${ }^{14} \mathrm{~K}$ arpel, M., ID esign for Active Flutter Suppression and Gust Alleviation U sing State-Space A eroelastic M odeling," J ornal of Aircraft, Vol. 19, No. 3, 1982, pp. $221\{227$.

15 Lazarus, K. B. and Crawley, E. F., \Multivariable High-A uthority Control of Plate-Like Active Structures," 33rd AIAA/ASME/ASCE/AHS/ASC Structures, Structural Dynamics and M aterials, Dallas, TX, A IA A-92-2529-CP, A pr. 13-15 1992, pp. $931\{945$.

${ }^{16}$ Conner, M. D., Tang, D., Dowell, E. H., and Virgin, L. N., \Nonlinear B ehavior of a Typical Airfoil Section with Control Surface Freeplay: A Numerical and Experimental Study," J ournal of Fluids and Structures, Vol. 11, 1997, pp. 89\{109.

17 Conner, M. D., Nonlinear Aeroelasticity of an Airfoil Section With Control Surface Freeplay, Ph.D. thesis, Duke University, Durham, NC 27708, 1996.

18 Doyle, J. C., Glover, K., K hargonekar, P. P., and Francis, B. A., IState-Space Solutions to Standard $\mathrm{H}_{2} / \mathrm{H}_{1}$ Control Problems," IEEE Transactions on Automatic Control, Vol. 34, No. 8,1989, pp. $831\{847$.

${ }^{19}$ R oark, R. J . and Young, W. C., Roark's Formulas for Stress and strain, M cG raw-Hill, New York, 1989.

20 Oppenheim, A. V. and Schafer, R. W ., Digital Signal Processing, Prentice\{Hall, Inc., Englewood Clißs, NJ 07632, 1975.

${ }^{21}$ Active Control eXperts, Inc., 215 First Street, Cambridge MA, 12142, Smart ID System Identi ${ }^{-}$cation Software. 


\section{List of Figures}

1 Diagram of Two-P ort Control Con ${ }^{-}$guration $\ldots \ldots \ldots 16$

2 Composite Closed-loop System . . . . . . . . . . . . . . . . . . . . . . . . 17

3 P hotograph of the Experimental M odel, as M ounted in the Duke University LowSpeed $W$ ind Tunnel . . . . . . . . . . . . . . . . . . . . . . . . . . . . . 18

4 Photograph Showing Top Views of the Experimental Model and the Support Structure, as Mounted in the Duke University Low-Speed Wind Tunnel; The A irfoil and Flap Can be Seen Through the Clear, Top Wall of the W ind Tunnel

5 Schematic Diagram of Experimental Control Assembly . . . . . . . . . . . . 20

6 Picture of Control Assembly With Bottom Wall of W ind Tunnel Removed . . . 21

7 Measured (| \{) and M odeled (- - -) Frequency Response of the Three Observed System Variables . . . . . . . . . . . . . . . . . . . .

8 Analytical and Experimental FRFs at a Flow of $18.1 \mathrm{~m} / \mathrm{s}$; Open-loop (| \{); Closed-loop $\left(--^{-}\right) \ldots \ldots \ldots \ldots \ldots \ldots$

9 Transient Response W ith and W ithout Control at a F low of $12.5 \mathrm{~m} / \mathrm{s}$; O pen-loop (| \{); Closed-loop $\left(--^{-)} \ldots \ldots \ldots \ldots\right.$

10 Open (| \{) and Closed-loop (- - ) Response at a Flow of $18.1 \mathrm{~m} / \mathrm{s} \ldots \ldots 25$

11 Transient Response With (- - ) and W ithout (| \{) Control at a Flow of $18.1 \mathrm{~m} / \mathrm{s} 26$

12 Unstable Transient Response Without Control at a Flow of $18.6 \mathrm{~m} / \mathrm{s} \ldots 27$

13 Closed-Loop Transient Response 8.1\% A bove the Uncontrolled Flutter Boundary 28

14 Closed-loop Frequency Responses for 20.1 and $20.9 \mathrm{~m} / \mathrm{s}$ Flowrates . . . . . . 29

15 Open (| \{) and Closed-loop (- - ) FRFs for $0 \stackrel{\circledR}{\circledR}$ Nominal Flowrates . . . . . 30 


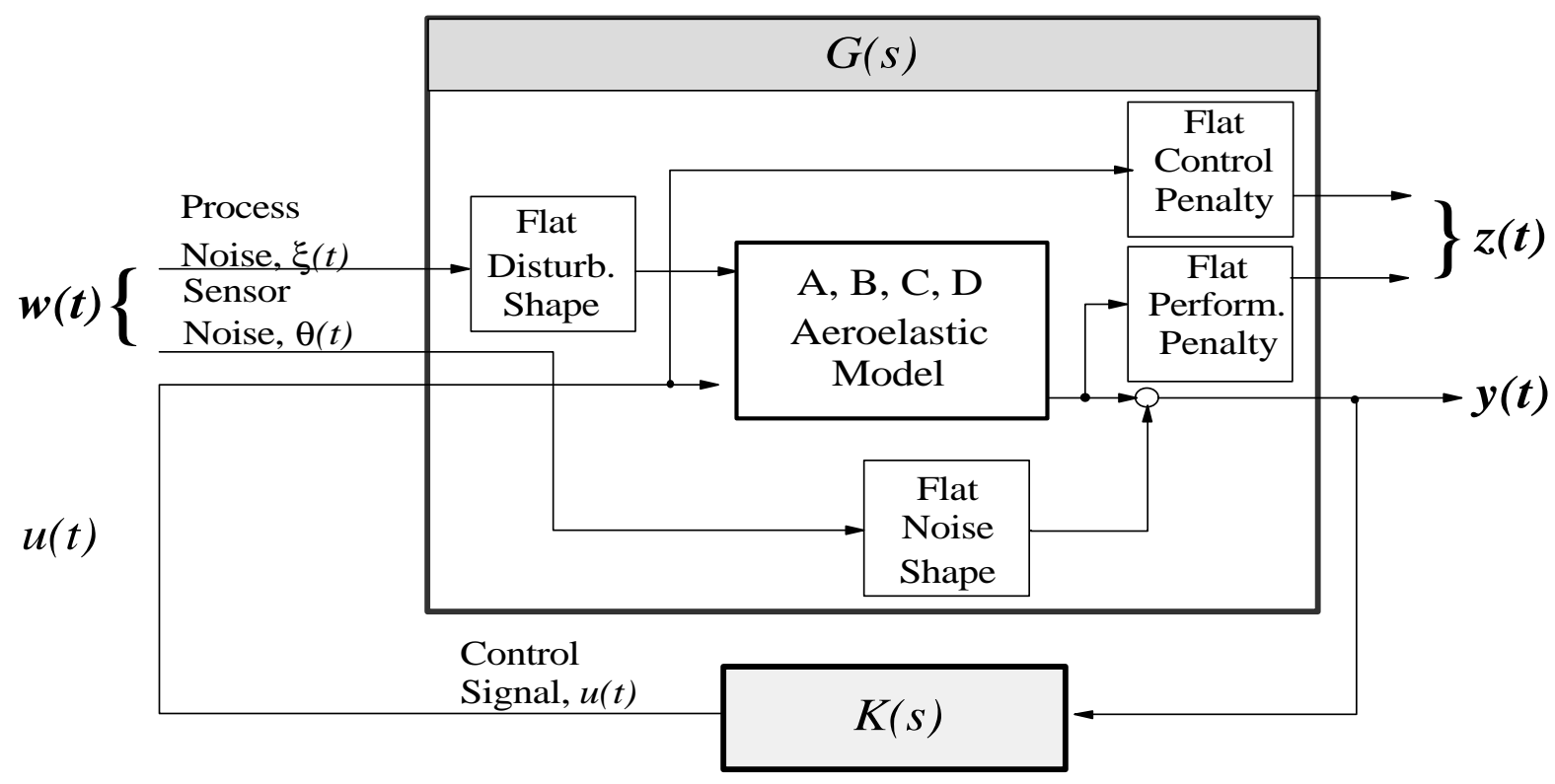

Figure 1: Diagram of Two-Port Control Con ${ }^{-}$guration 


\section{Augmented System}

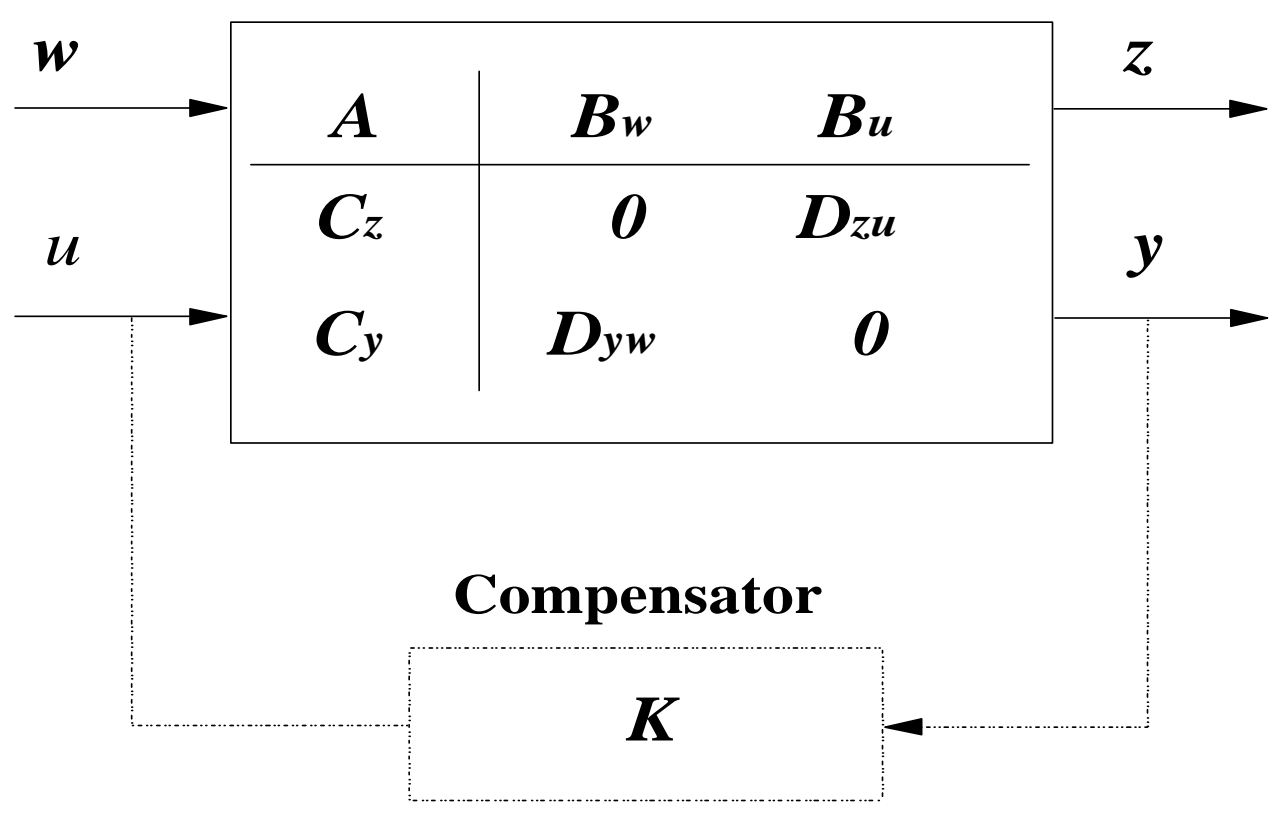

Figure 2: Composite Closed-loop System 


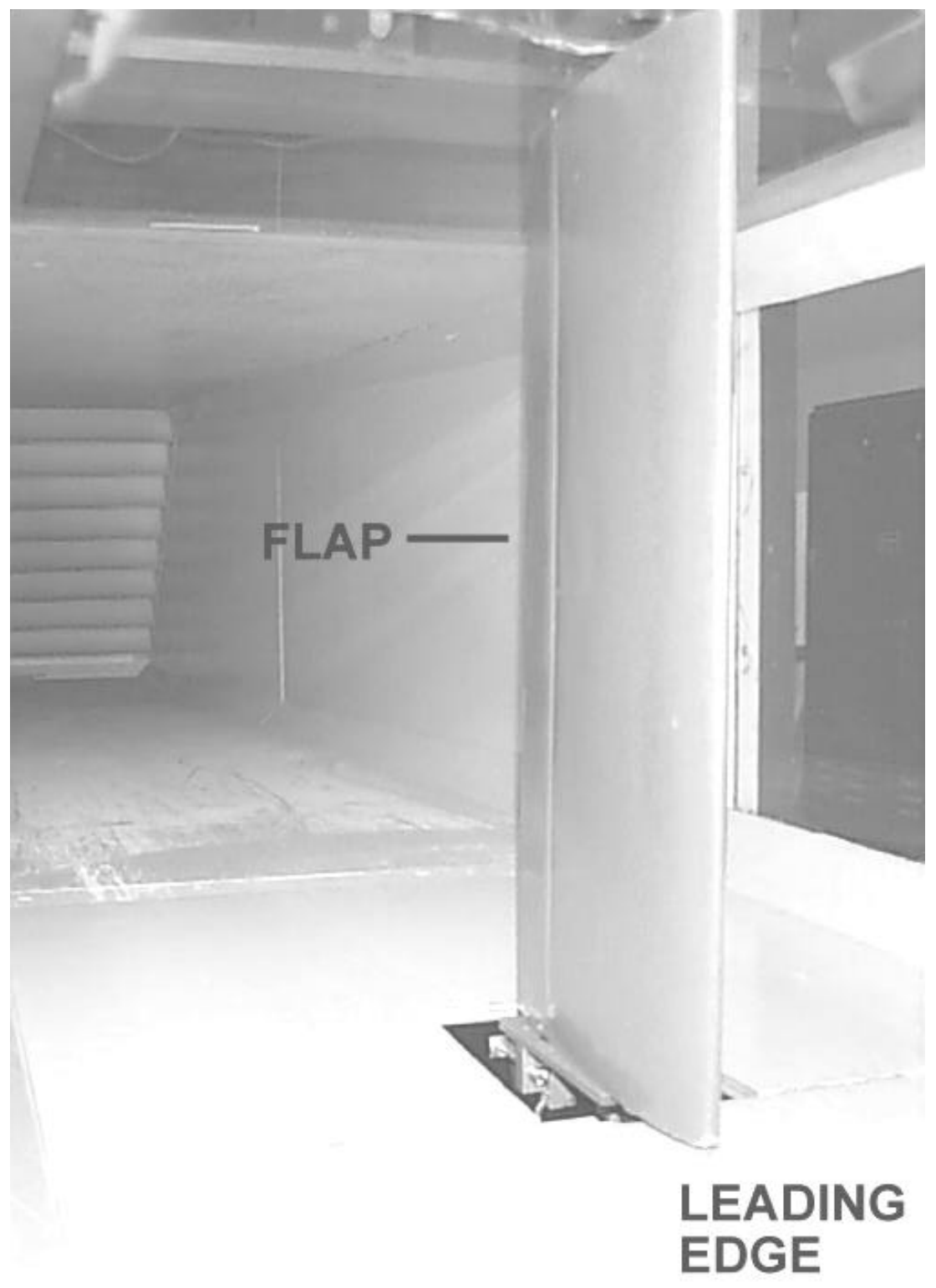

Figure 3: P hotograph of the Experimental M odel, as M ounted in the Duke University Low-Speed Wind Tunnel 


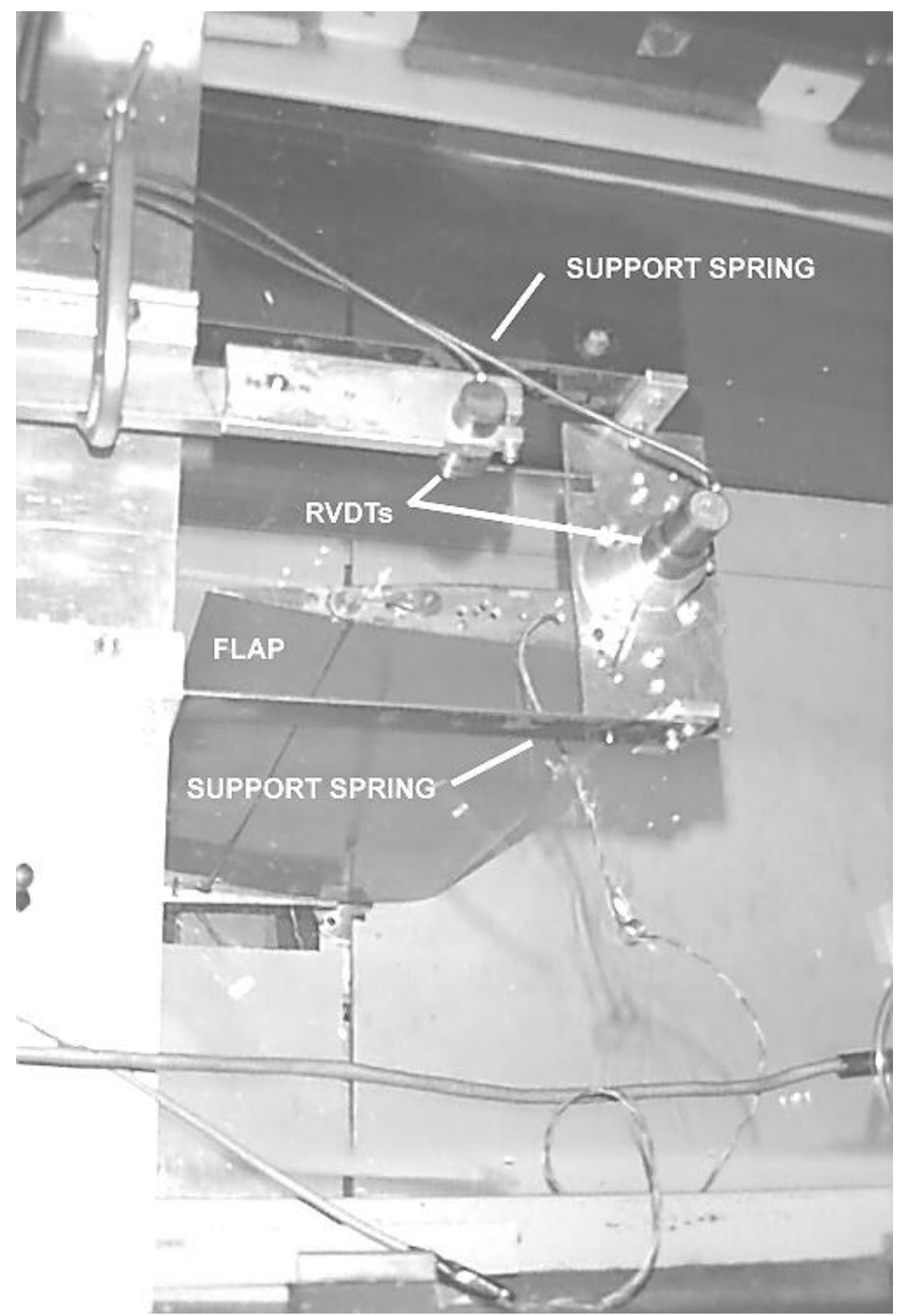

Figure 4: P hotograph Showing Top V iews of the Experimental M odel and the Support Structure, as M ounted in the Duke University Low-Speed W ind Tunnel; The A irfoil and Flap Can be Seen Through the Clear, Top Wall of the W ind Tunnel 


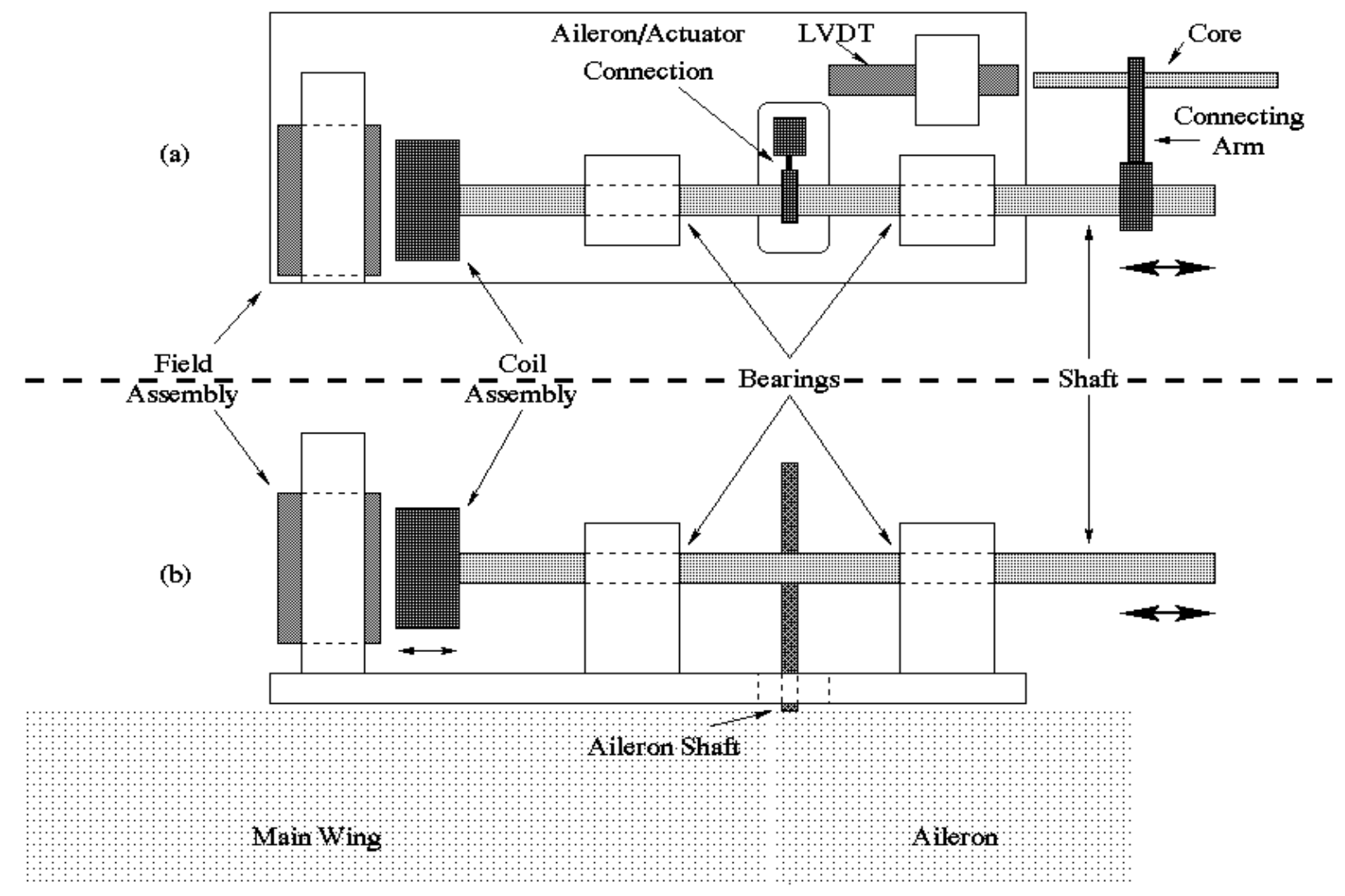

Figure 5: Schematic Diagram of Experimental Control Assembly 


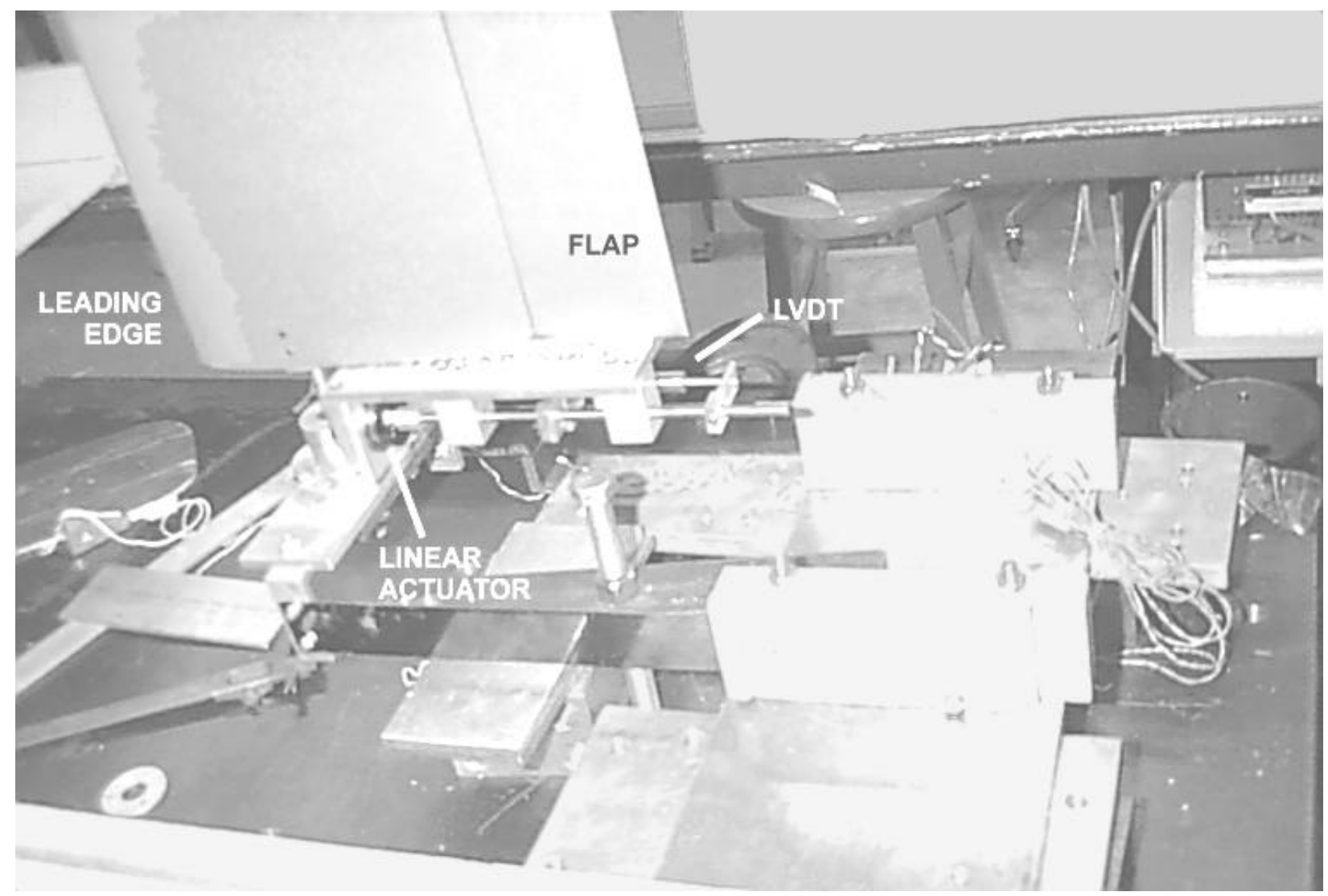

Figure 6: Picture of Control A ssembly With Bottom Wall of Wind Tunnel Removed 

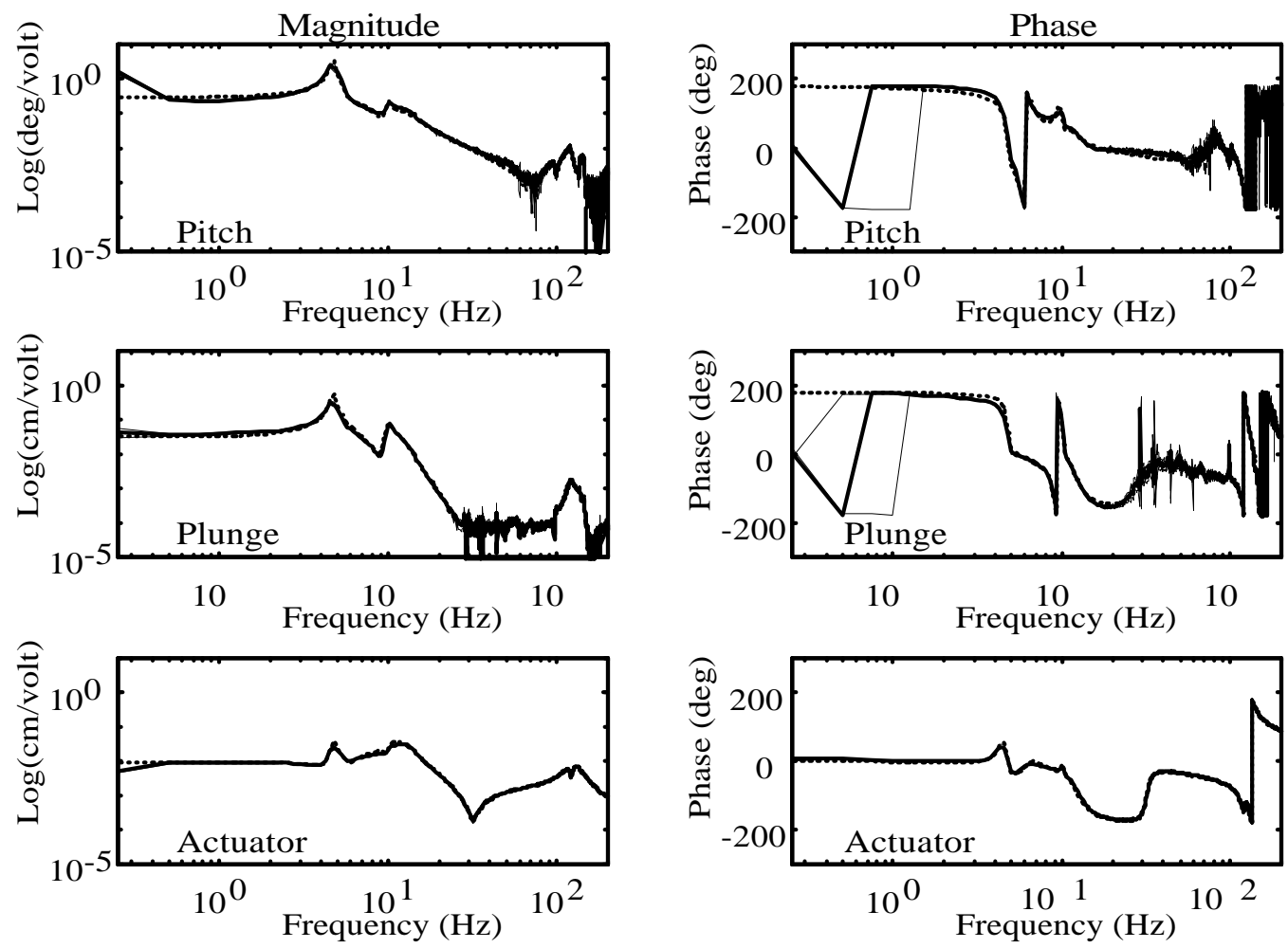

Figure 7: Measured (| \{) and Modeled (- - -) Frequency Response of the Three Observed System Variables 

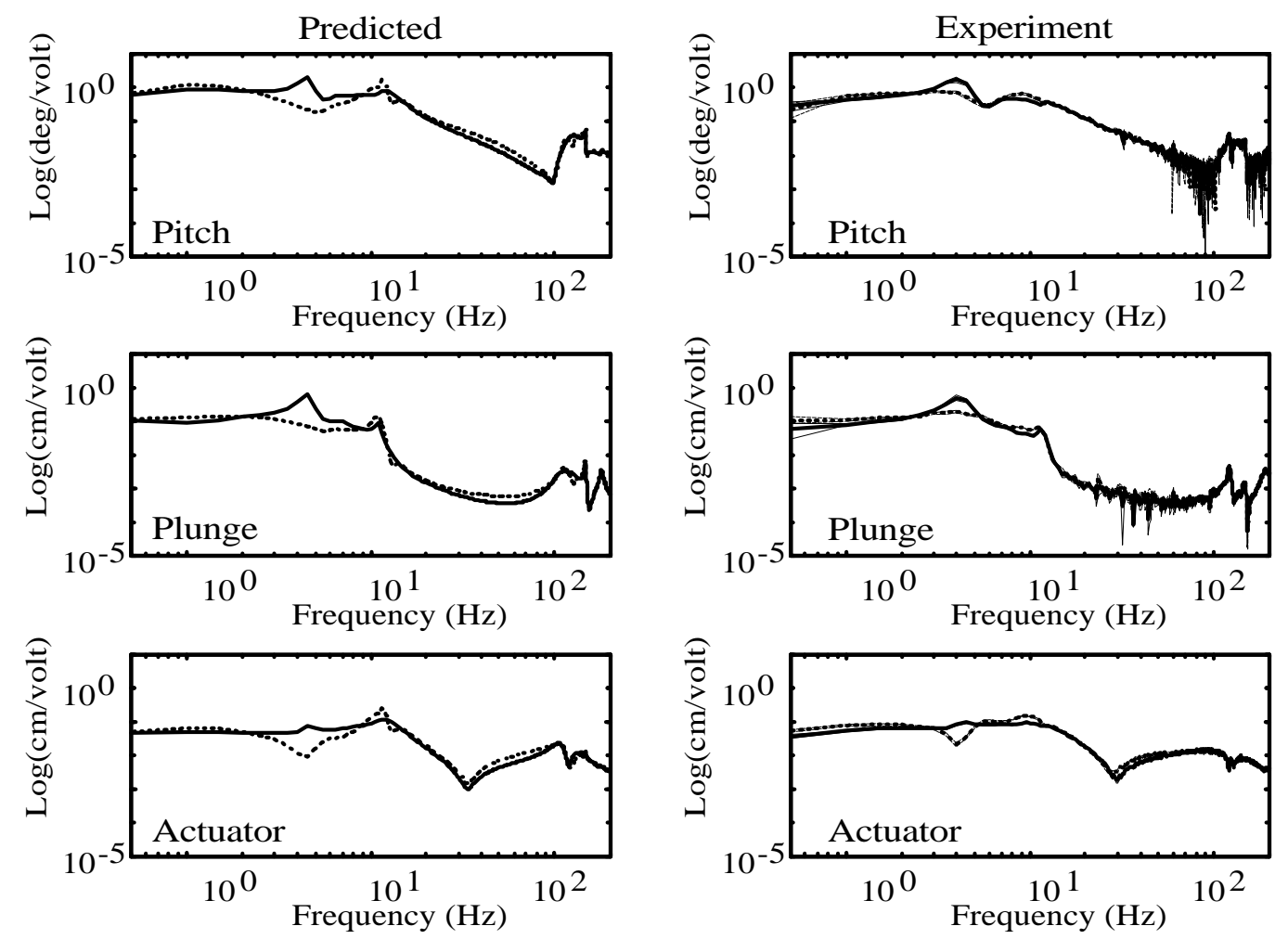

Figure 8: Analytical and Experimental FRFs at a Flow of $18.1 \mathrm{~m} / \mathrm{s}$; Open-loop (I \{); Closedloop (- - -) 

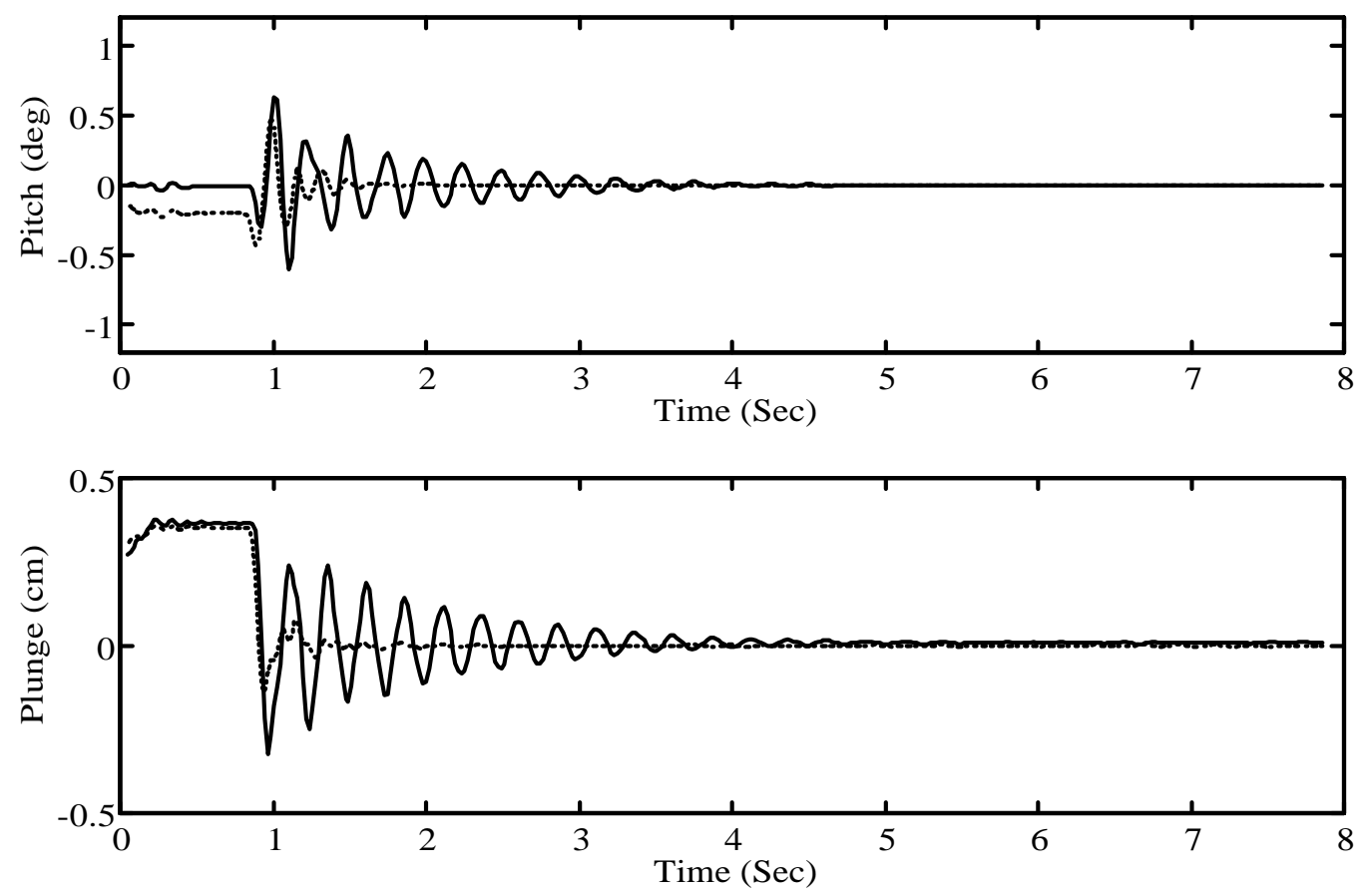

Figure 9: Transient Response With and Without Control at a Flow of $12.5 \mathrm{~m} / \mathrm{s}$; Open-loop (| \{); Closed-loop (- - -) 

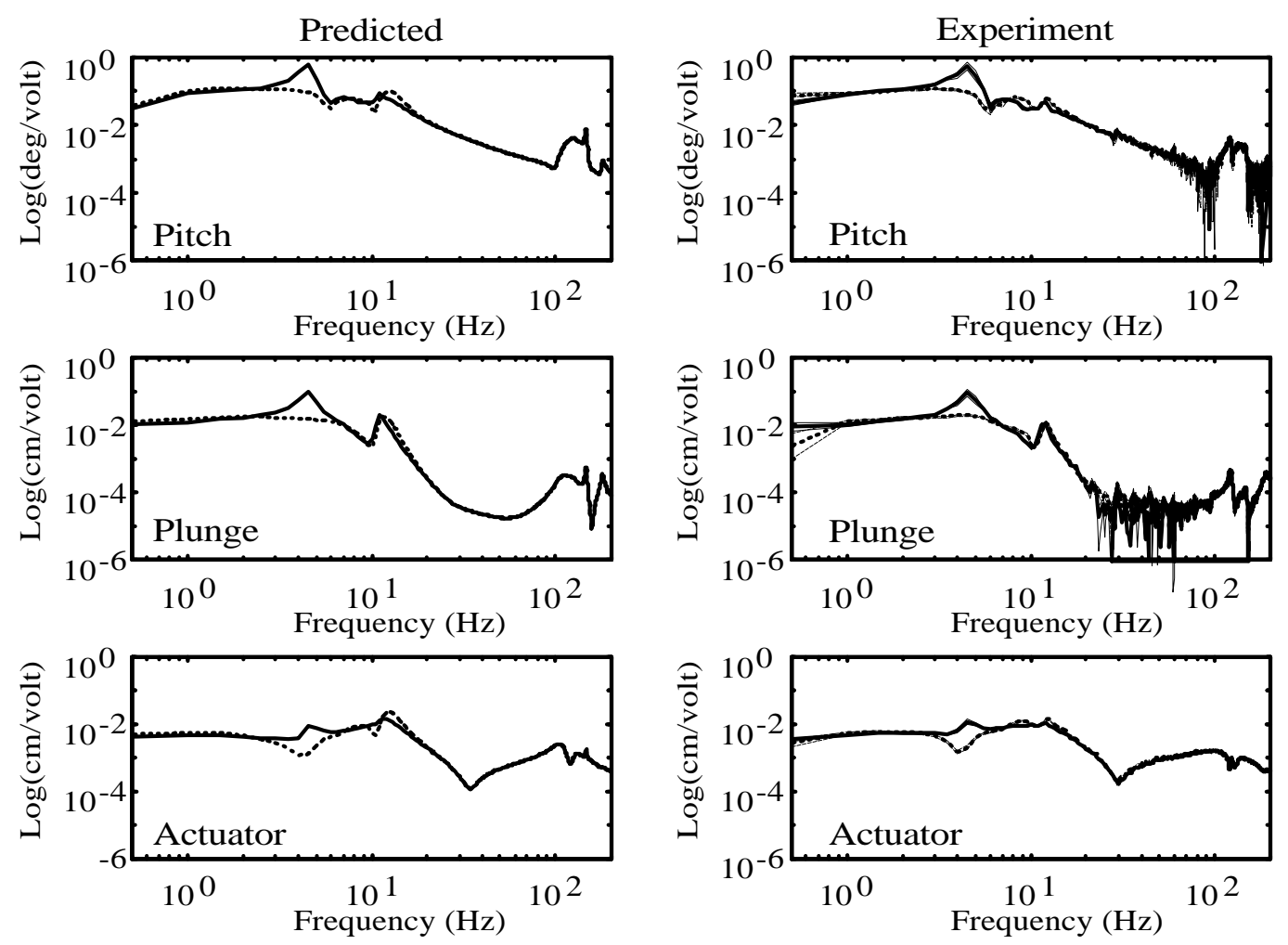

Figure 10: Open (| \{) and Closed-loop (- - ) Response at a Flow of $18.1 \mathrm{~m} / \mathrm{s}$ 

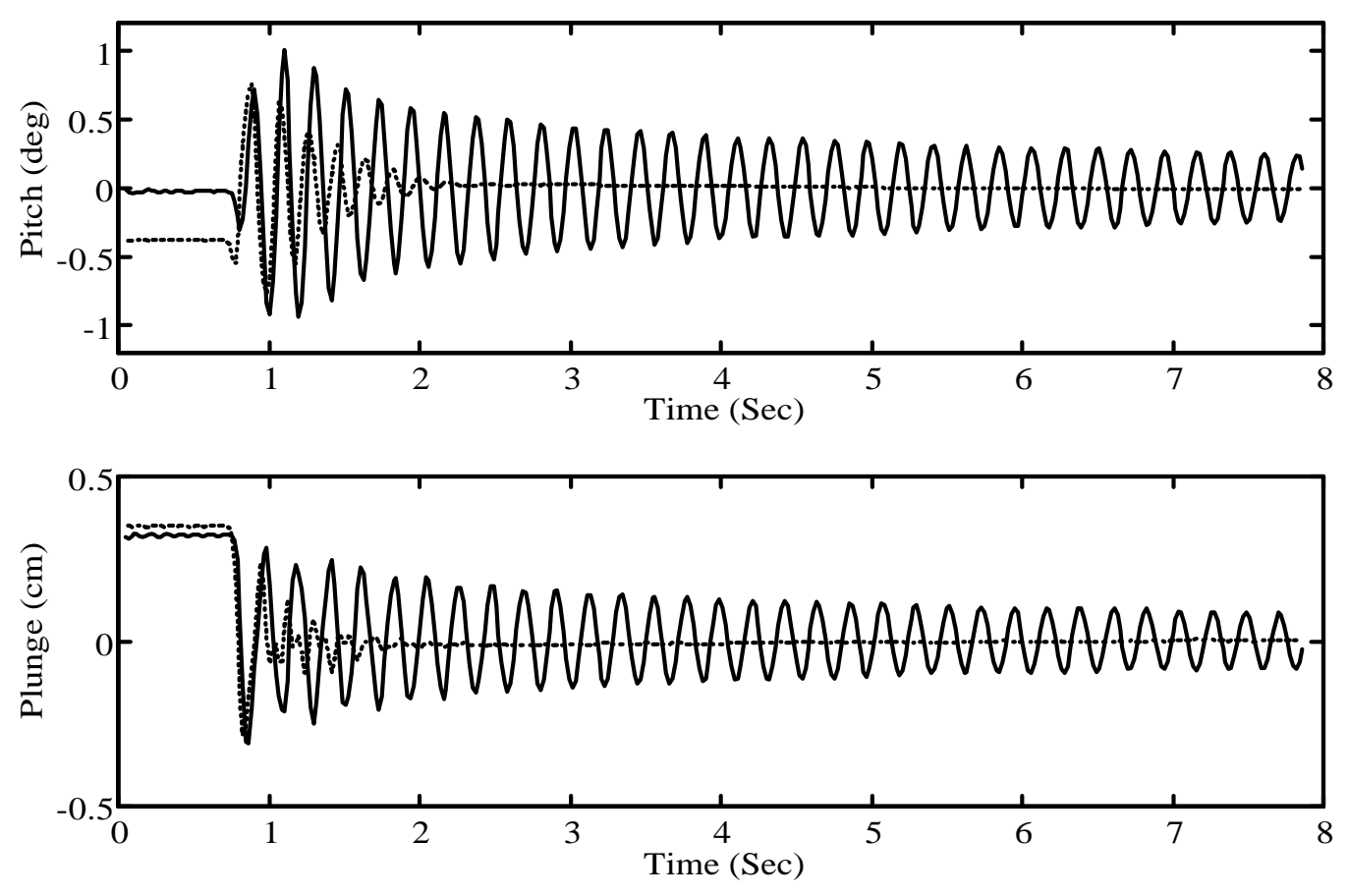

Figure 11: Transient Response With (- - ) and Without (| f) Control at a Flow of $18.1 \mathrm{~m} / \mathrm{s}$ 

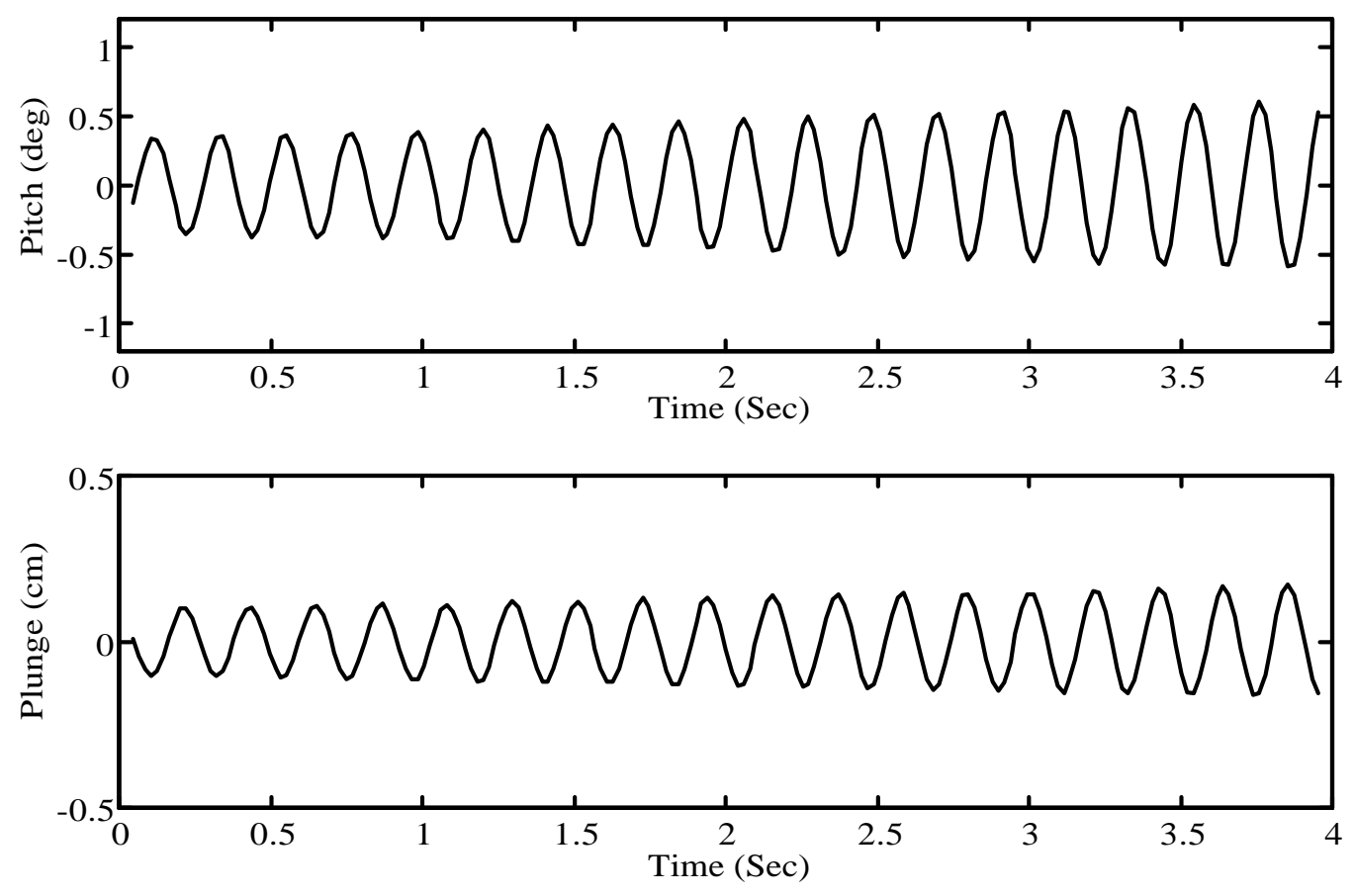

Figure 12: Unstable Transient Response W ithout Control at a Flow of $18.6 \mathrm{~m} / \mathrm{s}$ 

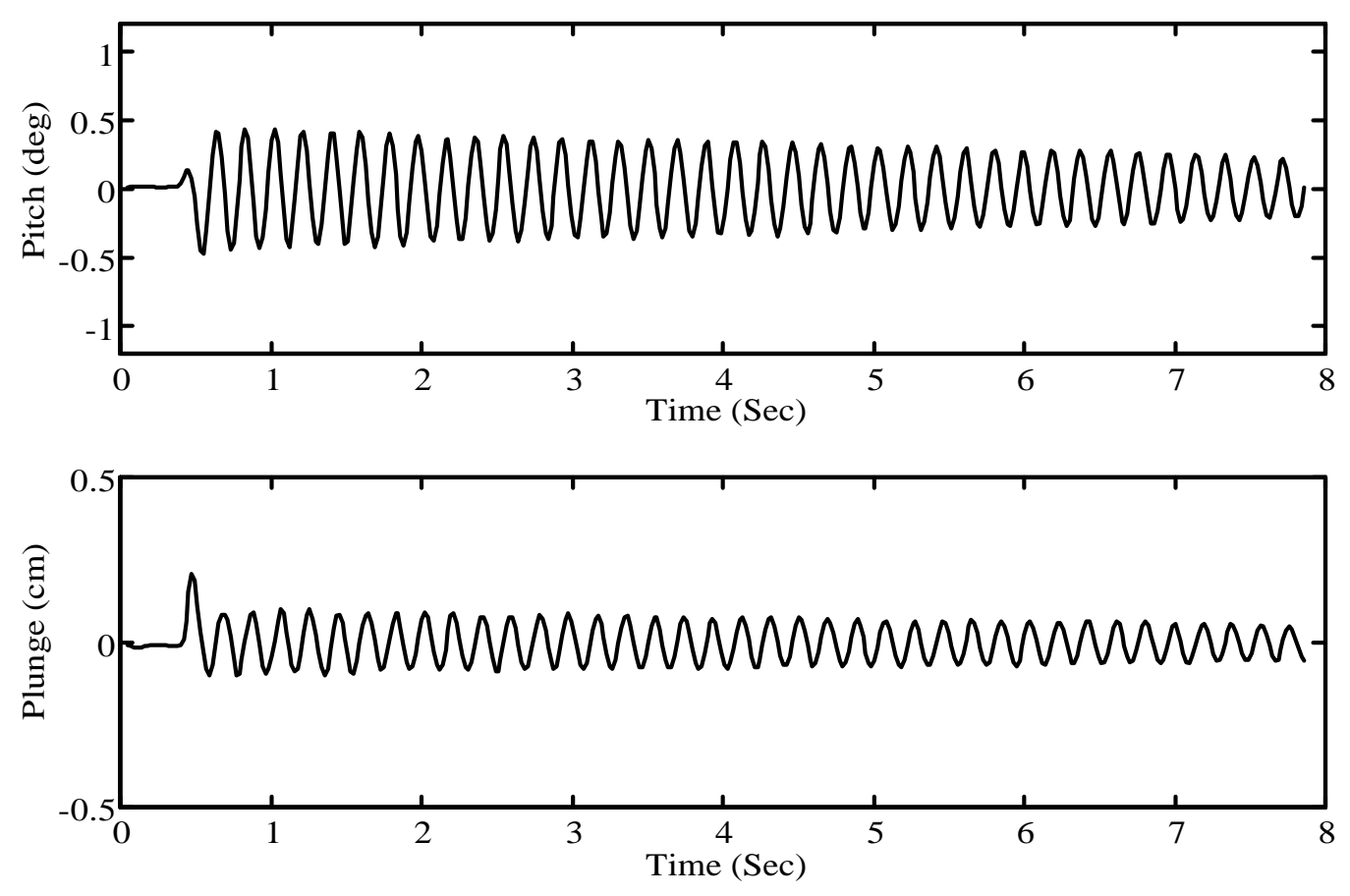

Figure 13: Closed-Loop Transient Response 8.1\% A bove the Uncontrolled Flutter Boundary 


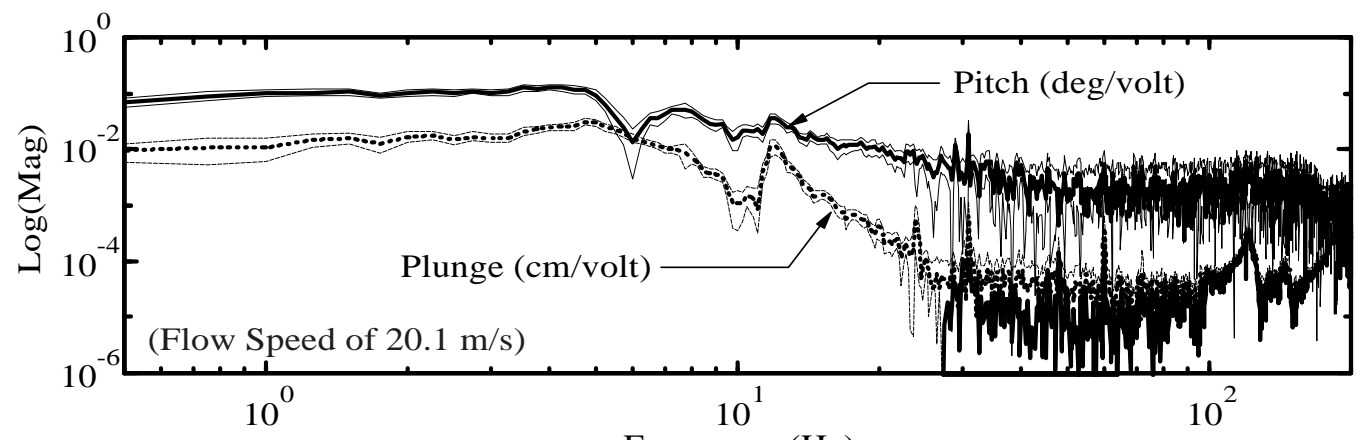

Frequency (Hz)

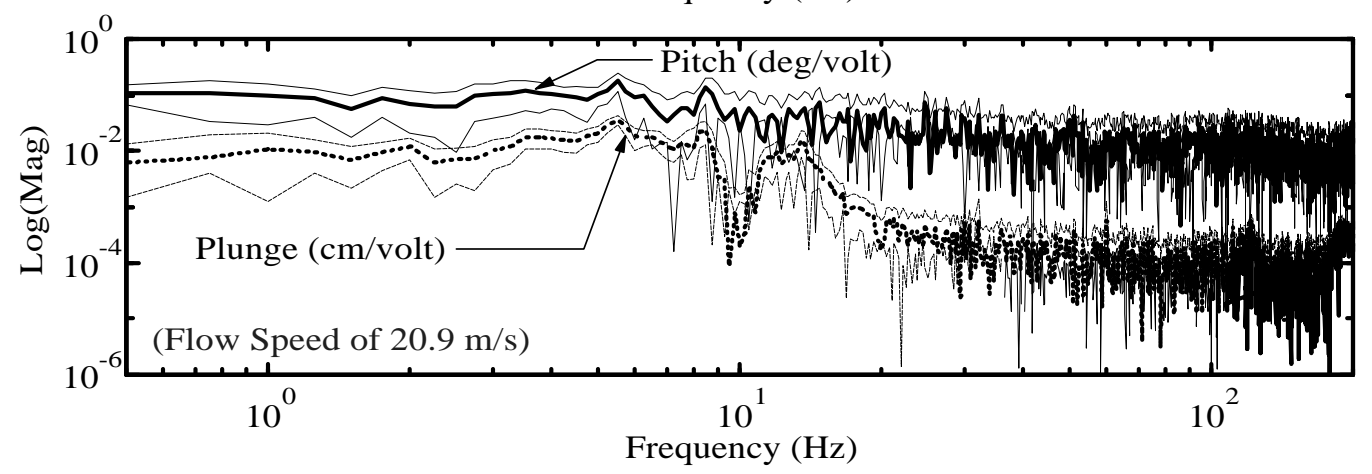

Figure 14: Closed-loop Frequency Responses for 20.1 and $20.9 \mathrm{~m} / \mathrm{s}$ Flowrates 

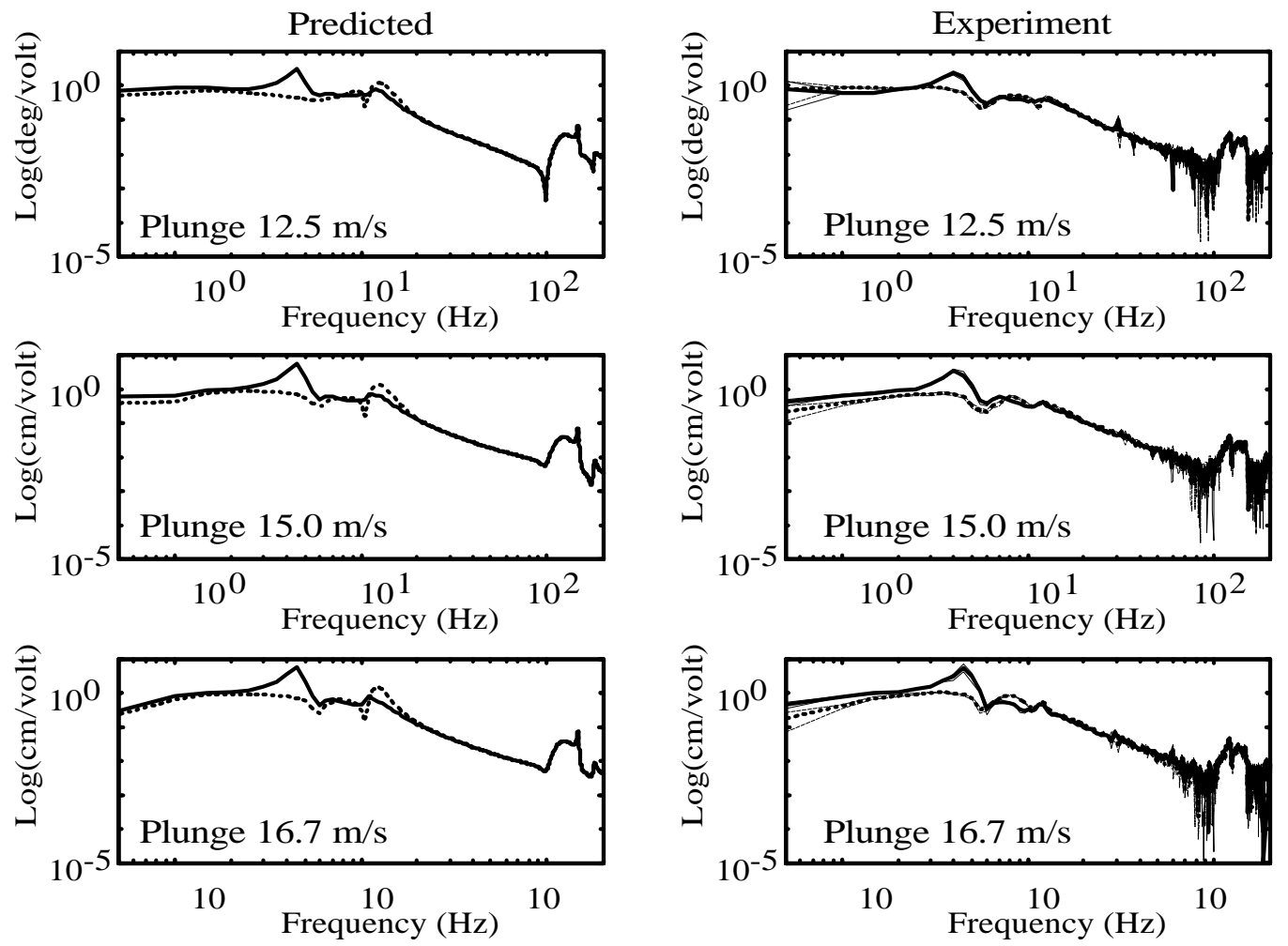

Figure 15: Open (| \{) and Closed-loop (- - -) FRFs for O \&N ominal Flowrates 